\title{
Exploration on the Transformation of Applied Undergraduate Scientific Research Achievements Into Teaching Resources \\ - Taking the Design and Development of Vacuum Non-consumable Arc Furnace Equipment System as an Example
}

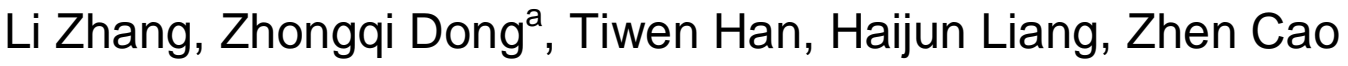 \\ Hebei College of Industry and Technology, Shijiazhuang 050000, China. \\ adongzhongqi@126.com
}

\begin{abstract}
Based on the research project of design and development of vacuum non-consumable arc furnace equipment system, this paper explores the ways and methods of transforming scientific research achievements into high-quality teaching resources for applied technology undergraduate students. Through the design and development of electric arc furnace equipment system, a new type of electric arc furnace equipment has been constructed, which makes smelting operation safe, energy saving convenient for students to do experiments, and promotes students' innovative ability. It has greatly improved the quality of education and teaching for undergraduates majoring in metallurgical technology.
\end{abstract}

Keywords: electric arc furnace equipment system, scientific research achievements, teaching resources.

\section{Introduction}

As the main position of talent training, colleges and universities should guide, encourage scientific research personnel to teach and educate people, pay attention to the diffusion and transfer of knowledge, transform the scientific research achievements into education and teaching in time, develop the resources of subjects and specialties, and improve the quality of talent training [1 - 6]. The applied undergraduate course is guided by the application of scientific knowledge and technical achievements [2]. The teaching of its course requires the cultivation of students' practical application ability to meet the actual needs of the industry and the construction of students' core literacy to solve practical application problems [7 - 12]. Because of the comprehensive and practical characteristics of the industry itself, in recent years, the employers' ability to apply to the students has been improved day by day, which requires the teaching of applied courses to pay more attention to the combination of theory and practice. Therefore, it is the best way to change the scientific research results into teaching resources. In this paper, the scientific research project results of electric arc furnace equipment system design and development are transformed into the teaching resources of applied undergraduate students of metallurgical engineering technology, and the transformation methods and ways are explored.

\section{Brief Introduction of Scientific Research Achievements}

\subsection{Project Profile}

The electric arc furnace is the equipment which uses the electrode arc to produce the high temperature to carry on the melting to the metal material, according to whether the electrode is consumed in the melting process, divides into the self-consumption furnace and the non-self-consumption furnace. the non-self-powered arc furnace uses non-consuming materials such as tungsten needle or graphite as the electrode. when melting, the electrode is used as the cathode, and the molten metal is used as the anode. between the cathode and the anode, the metal is melted by arc discharge to produce high temperature.

At present, the electric arc furnace used in the laboratory adopts the way of manually adjusting the electrode position. Before the experiment, the electrode is manually controlled to drop and contact 
the melt, and the electrode is manually controlled to rise after the arc. However, the accuracy of manual control is low, and the electrode cannot be lifted quickly after arc, which will prolong the contact time between the electrode and the melt, which will lead to the electrode contamination of the melt.

In view of this, this scientific research project carries on the system design to the electric arc furnace, in order to solve the problem that the existing electric arc furnace cannot accurately control the electrode.

\subsection{The Core Issues of the Study}

(1) The vacuum system of vacuum non-consumable arc furnace equipment is established, the vacuum degree of the system can be measured, and the vacuum can be monitored and recorded in real time by the display instrument.

(2) The tungsten electrode and molten pool melting system of vacuum non-consumable arc furnace equipment is designed. The power of the system can be measured and can be adjusted and controlled in real time through the regulator to display the monitoring and recording of the instrument.

(3) The water-cooling system of vacuum non-consumable arc furnace equipment is designed. The system pressure can be measured and monitored and recorded by recording instrument.

(4) The electrode control system of vacuum non-consumable arc furnace equipment is designed, and the electrode lifting and lifting is accurately controlled by servo motor and pid control system.

\subsection{Experimental Platform Built by the Project}

The research group has constructed the following systems to study several problems involved in the project:

(1) The vacuum system of vacuum non-consumable electric arc furnace equipment is constructed, and the low and high vacuum of the newly designed equipment is detected online and in real time by vacuum gauge, resistance gauge and ionization gauge.

(2) The melting system of vacuum non-consumable arc furnace equipment is constructed. The conical high purity tungsten rod is used as the electrode and the water-cooled copper crucible is used as the molten pool to realize the non-consumable melting of the electrode.

(3) The water-cooling system of vacuum non-consumable electric arc furnace equipment is constructed, and the furnace body and molten pool of electric arc furnace are cooled in real time through water storage tank, water cooling pipe and self-priming feed water pump.

(4) The electrode control system of vacuum non-consumable arc furnace equipment is constructed, and the electrode rise and fall is accurately controlled by servo motor and pid control system.

\subsection{Scientific Research Results of the Project}

Through the redesign of vacuum non-consumable arc furnace equipment and the transformation of the design results into practical equipment, the operation test obtains the following beneficial results:

(1) the safety is greatly improved, and the operation is easier and safer through the real-time control of vacuum system, cooling system, melting system and electrode system.

(2) The electric arc furnace can accurately control the position of the electrode, so that the electrode can be promoted rapidly after the electrode is electrified and arc, to avoid the contamination of the melt caused by the long contact between the electrode and the melt.

(3) The energy consumption of the new vacuum non-consumable arc furnace equipment is reduced, and the energy saving meets the requirements of green metallurgy.

\section{The Application of Scientific Research Achievements in Teaching}

The research results of this project not only provide a new type of arc melting equipment for practical engineering application design, but also provide a production technology for engineering application, and can also meet the needs of teaching and scientific research. After the completion of 
the project, the research group applied the results of the project to the teaching of EAF steelmaking production equipment and process, and transformed it into the teaching resources of the course perfectly.

(1) The research results of vacuum non-consumable arc furnace equipment system design and development have been formally included in the experimental syllabus of metallurgical engineering technology.

(2) The electric arc furnace prepared by the experiment of this project has become the equipment resource. The application of the equipment in the experimental teaching has the advantages of safety and energy saving, simple operation, greatly alleviated the experimental pressure of the students, and achieved satisfactory teaching effect.

(3) The electric arc furnace has become a resource of scientific research equipment. Students can melt and prepare new alloy materials through the equipment, contact the frontier achievements of the subject at close range, improve students' interest in learning, broaden students' field of vision, and provide a good platform for cultivating students' practical innovation ability.

(4) By leading students to participate in the implementation of the project, students can improve their operational ability and problem-solving ability, and stimulate students' innovative consciousness.

(5) It is useful for graduation design to apply the scientific research results to students' graduation thesis writing and to enhance students' interest and ability to solve practical engineering problems.

\section{Conclusion}

The training goal of teaching talents in application-oriented colleges and universities is to send a large number of excellent talents with basic professional knowledge and practical ability to the society [13 - 15]. The teachers of scientific research projects turn scientific research achievements into highquality teaching resources for metallurgical engineering and technology majors around the practical requirements of applied technology, introduce scientific research achievements into classroom teaching reform, and reform the curriculum teaching system. At the same time, according to the professional characteristics of metallurgical engineering technology, we should establish an innovative work platform with students' core so that students can carry out practical operation. At the same time, by leading students to participate in scientific research practice, we should improve students' professional level and practical innovation ability, to meet the goal of application-oriented undergraduate training.

\section{Acknowledgements}

This work was financially supported by Hebei University Humanities and Social Sciences Research Project (2018201027308) and Hebei Vocational College of Technology Project (SKZ201802) and (ZKZ2019001).

\section{References}

[1]. Chen Liang, Chen Zheny. Research on the teaching transformation mechanism of scientific research achievements of university and enterprise Co- construction research center of furniture design specialty [J]. Design, 2019 (05): 82-84.

[2]. Zhu Ping, Yan Ruping, Liu Dezhou. Review Achievements of Education Research and Education Reform in Affiliated Hospitals of Medical Universities from the Perspective of Teaching Resource Transformation [J]. Hospital Management Forum, 2019, 36 (02): 51 - 52.

[3]. Jin Hong. Research on the path of transforming scientific research achievements into teaching resources [J]. Western China Quality Education, 2018, 4 (19): 155-157. 
[4]. Pei Zhengbing, Tian Caiyun. A study on the significance, Foundation and Model of the Teaching case of the Transformation of Scientific Research achievements of Teachers in Colleges and Universities [J]. Journal of Higher Education, 2018 (17): 82-85.

[5]. Zhang Heqiu, Liang Hongwei, Hu Lizhong, et al. Exploration and Practice of the Transformation of Scientific Research Resources into Teaching Resources [J]. Education Teaching Forum, 2018 (31): 145-146.

[6]. Lin Qinghe. Exploring the effective Mechanism of the Transformation from the Scientific Research Achievement of Business Administration to the Teaching case [A]. Advanced Science and Industry Research Center. Proceedings of 2018 International Conference on Education Reform and Management Science (ERMS2018) [C]. Advanced Science and Industry Research Center: Science and Engineering Research Center, 2018:6.

[7]. Yu Ye, Wang Li. Discussion on Transformation of Geological Research Achievements into Undergraduate Teaching Resources [J]. The Guide of Science \& Education, 2018 (04): 63-64.

[8]. Xie Dan. Study of transforming scientific research achievements into teaching resources in universities -A case of S university [D]. Southwest University, 2018.

[9]. Wang Hongbin. On the Transformation of Academic Resources from the Perspective of the Integration of Science and Education [J]. Journal of Hunan Radio and Television University, 2018 (01): 82-87.

[10]. Yu Ye, Xiao Yongjun, Wang Li. Exploration of Transforming Scientific Research Achievements into Teaching Resources [J]. Theory and Practice of Contemporary Education, 2018, 10 (02): 76-79.

[11]. Cao Zhenhua, Sun Binbin. On the Transformation of Scientific Research achievements into Teaching Resources-Research on variable Air Volume Air Conditioning Control system [J]. West Leather, 2017, 39 (24): 51-61.

[12]. Wu Zhiqiang, Zhu Aimin, Lu Liwei. Reflections on the transformation of scientific research results into teaching resources in the field of view of undergraduate teaching review [J]. Theory and Practice of Contemporary Education, 2017, 9 (06): 105-107.

[13]. Wang Shu-min, Ding Wuquan, Xu Qiang, et al. Study on Construction of "Four Integration" and Cultivation of Applied Talents [J]. Guangzhou Chemical Industry, 2017, 45 (10): 171-173.

[14]. Du Gang, Yang Cong. The application of research achievements to teaching resources in chemical engineering course [J]. Technology and Market, 2017, 24 (04): 266-267.

[15]. Sun Binbin, Yang Cong. The Case of Scientific Research into Teaching Resources-Design and Production of the Ball-and-stick Models of Ethane and Ethyne [J]. Guangdong Chemical Industry, 2017, 44 (05): 217-218. 